\title{
Study of the Dielectric Response of Ester Impregnated Cellulose for Moisture Content Evaluation
}

\author{
A. Graczkowski, J. Gielniak, P. Przybyłek, K. Walczak, H. Morańda \\ Poznan University of Technology, Institute of Electric Power Engineering
}

\begin{abstract}
Knowledge about moisture content in impregnated cellulose insulation is essential for power transformers when estimating remaining lifetime, planning operating conditions and drying procedure. Frequency dielectric spectroscopy (FDS) is non-destructive, convenient method to asses moisture content of insulation. It is important to study dielectric response of ester-cellulose insulation due to growing number of transformers using synthetic ester MIDEL 7131 as insulation fluid [1, 2]. The paper presents study of dielectric response of synthetic ester-pressboard samples with various moisture content (from dry to $5 \%$ ) measured in wide temperature range (from $5{ }^{\circ} \mathrm{C}$ to $50{ }^{\circ} \mathrm{C}$ ). Measurement results for pressboard impregnated with synthetic ester are compared to data of pressboard impregnated with mineral oil. The aim of presented work is to provide patterns of dielectric response of synthetic esterpressboard for accurate moisture content evaluation.
\end{abstract}

\section{Introduction}

The frequency dielectric spectroscopy (FDS) is a widely used technique, recommended in insulation systems diagnostics. It is nowadays popular for water content evaluation in solid insulation of power transformers. Insulation system of typical power transformer consists of oil and impregnated cellulose in the form of pressboard and paper. In most cases mineral oil is used as impregnating liquid.

The evaluation of water content using FDS is based on dielectric response patterns of impregnated pressboard for various moisture content, which contains characteristics of mineral oil impregnated pressboard. Recently dielectric liquids like MIDEL 7131 - the synthetic ester, are used as an alternative instead of mineral oil. MIDEL 7131 have several advantages such as fast and high biodegradation, high fire point and nontoxicity $[1,2]$.

It was observed that type of impregnating liquid has influence on dielectric response of pressboard $[3,4]$. Using patterns of oil-pressboard in evaluation of moisture content of ester-pressboard insulation can lower accuracy of this evaluation. Thus, it is required to investigate dielectric response of synthetic ester impregnated cellulose.
This paper presents the study of moisture and temperature influence on dielectric response of MIDELpressboard insulation.

\section{Experiment}

\subsection{Samples}

The pressboard samples, which were used for measurements, had a thickness of $0.5 \mathrm{~mm}$ and diameter of $57 \mathrm{~mm}$. The examined pressboard had a smooth surface without any pattern. Sample preparation included: drying, moisturizing and impregnation.

First, samples were dried in a vacuum-thermal chamber for 13 hours at a temperature of $100{ }^{\circ} \mathrm{C}$ and pressure of $50 \mathrm{~Pa}$. After drying samples absorbed moisture from surrounding air. Their weight was controlled by precise scale. Then, after reaching desired weight (moisture level), samples were put into container filled with ester. Synthetic organic ester MIDEL 7131 (provided by M\&I Materials Ltd.) was used for impregnation. Parameters of impregnating liquids are shown in the Table 1.

During the process of impregnation samples were kept in ester at temperature $60{ }^{\circ} \mathrm{C}$ for 48 hours. After preparation of the samples set (with desired moisture level), moisture content of one sample was checked by Karl Fischer titration technique. Three samples were selected for FDS measurement. When dielectric responses of samples were similar, measurement was carried out for three samples connected in parallel in the whole available frequency range. After dielectric measurements one sample was measured by Karl Fischer titration to confirm moisture content. It was planned to prepare six groups of samples with moisture content of $0,5 \%, 1 \%, 2 \%, 3 \%, 4 \%$ and $5 \%$. The experiment is not finished yet, so some of measurements need to be repeated or conducted. The plan of experiment is show in Table 2.

\subsection{Dielectric measurements}

The measurements were done using a Pax Diagnostic IDAX-300 dielectric spectrometer. Dielectric response of impregnated pressboard samples was investigated in frequency domain in the range from $0.1 \mathrm{mHz}$ to $1 \mathrm{kHz}$ in most cases at $10 \mathrm{~V}$ RMS. The influence of voltage on the dielectric response was checked in the voltage range 1-140 V RMS and was found not significant.

All dielectric measurements were repeated at four temperature levels in climate chamber i.e., 5, 20, 35, $50{ }^{\circ} \mathrm{C}$, starting from $5{ }^{\circ} \mathrm{C}$ and increasing to $50{ }^{\circ} \mathrm{C}$. 
Afterwards, additional measurement was performed at $20{ }^{\circ} \mathrm{C}$ again to check if characteristic is stable. Before starting the measurement, samples were kept at each temperature at least one day.

Measurement results for ester-pressboard samples were compared with results obtained for mineral oil-pressboard samples [5].

Table 1 - Parameters of impregnating liquids

\begin{tabular}{|c|c|c|c|c|}
\hline \multirow{2}{*}{$\begin{array}{c}\text { Liquid } \\
\text { type }\end{array}$} & \multicolumn{2}{|c|}{$\begin{array}{c}\text { Conductivity } \\
{[\mathrm{pS} / \mathrm{m}]}\end{array}$} & $\begin{array}{c}\text { Activation } \\
\text { energy } \\
{[\mathrm{eV}]}\end{array}$ & $\begin{array}{c}\text { Dielectric } \\
\text { permittivity } \\
{[-]}\end{array}$ \\
\cline { 2 - 3 } & $20^{\circ} \mathrm{C}$ & $40^{\circ} \mathrm{C}$ & & \\
\hline $\begin{array}{c}\text { mineral oil } \\
\text { Nynas } \\
\text { Nytro } \\
10 \text { GBN }\end{array}$ & 3.7 & 10.1 & 0.40 & 2.2 \\
\hline $\begin{array}{c}\text { synthetic } \\
\text { ester } \\
\text { MIDEL } \\
7131\end{array}$ & 12.7 & 44.4 & 0.49 & 3.0 \\
\hline
\end{tabular}

Table 2 - Plan of experiment

\begin{tabular}{|c|c|c|c|c|}
\hline moisture & \multicolumn{4}{|c|}{ temperature of measurement $\left[{ }^{\circ} \mathrm{C}\right]$} \\
\cline { 2 - 5 } content [\%] & 5 & 20 & 35 & 50 \\
\hline $0-0.5$ & to do & to do & to do & to do \\
\hline 1 & repeat & repeat & repeat & repeat \\
\hline 2 & done & done & done & done \\
\hline 3 & done & done & done & done \\
\hline 4 & done & done & done & done \\
\hline 5 & done & done & done & done \\
\hline
\end{tabular}

\subsection{Electrodes}

Water solubility in MIDEL 7131 is several times higher than in mineral oil $[1,2]$. Measurement procedure takes several days. So it is very important to prevent moisture migration between sample and surrounding ester. Because of that, special three-electrode system was designed (Fig. 1). Sample is kept between electrodes and sealed. Measuring electrode diameter is $40 \mathrm{~mm}$ and geometric capacitance of the system (for sample thickness $0.5 \mathrm{~mm}$ ) is about $22 \mathrm{pF}$. Electrode system was put in hermetic container (Fig. 2) and placed in climate chamber. Six identical electrode systems was prepared.

\section{Results}

Figure 3 presents influence of moisture on dielectric response of pressboard impregnated with synthetic ester MIDEL 7131 at temperature of $35{ }^{\circ} \mathrm{C}$. In the low frequency range dielectric loss $\varepsilon$ " strongly depends on moisture content. At high frequencies moisture influence is less significant. At $1 \mathrm{kHz} \varepsilon$ " for moisture content of $2 \%, 3 \% 4 \%$ is very similar. Real part of permittivity $\varepsilon^{\prime}$ also strongly depends on moisture and increases with decreasing frequency.

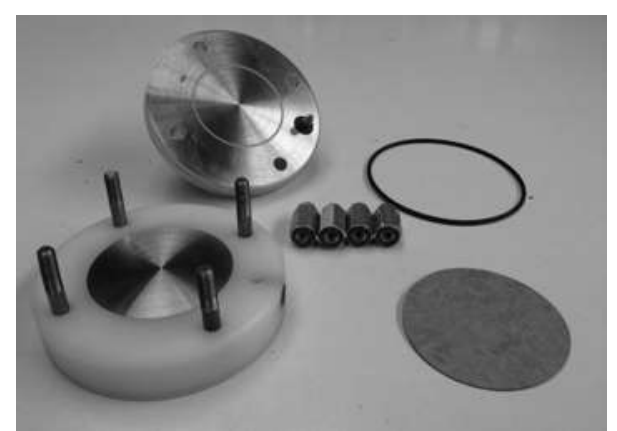

Fig. 1 - Electrode system with sealing rings and a sample

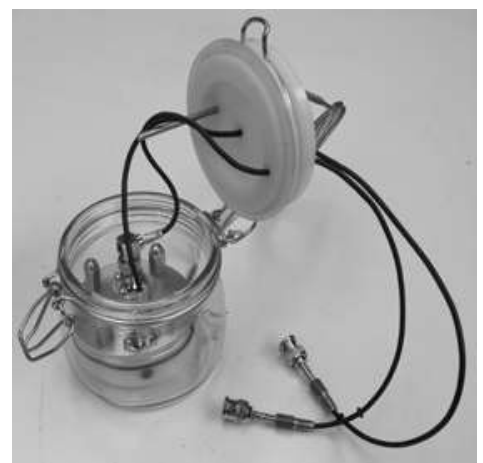

Fig. 2 - Electrode system in a hermetic container
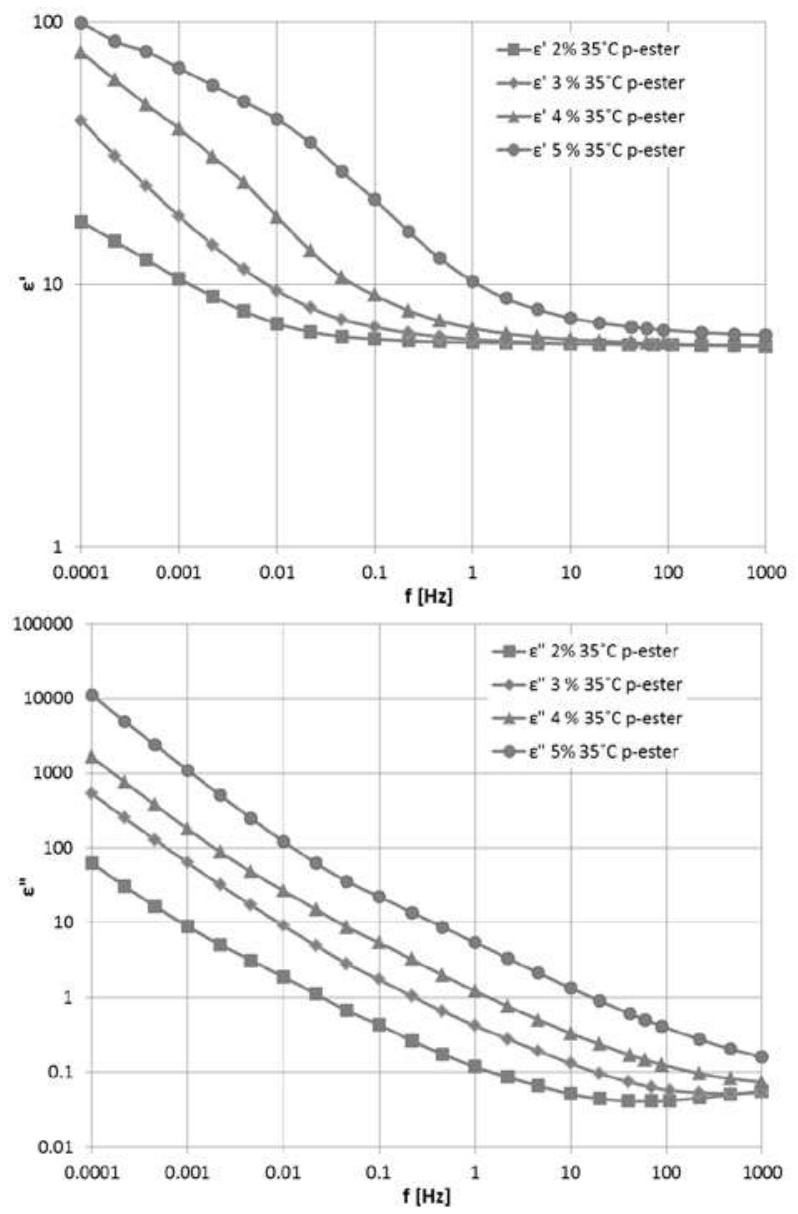

Fig. 3 - Dielectric response of synthetic ester impregnated pressboard at $35 \mathrm{C}^{\circ}$ with various moisture content: $2,3,4$, and $5 \%$ 
Dielectric response of impregnated pressboard is highly temperature dependent. Figure 4 shows results for esterpressboard samples with $2 \%$ of moisture at different temperature values. Characteristics for various temperatures can be normalized by shifting along frequency axes [6]. Activation energy for samples with $2 \%$ of moisture was calculated to be $0.8 \mathrm{eV}$. Figure 5 presents characteristics shifted to $50{ }^{\circ} \mathrm{C}$ for obtaining master curve.

Figure 6 and Figure 7 show the variation of the $\varepsilon^{\prime}$ and $\varepsilon$ " for the synthetic ester impregnated pressboard and mineral oil impregnated pressboard with $2 \%, 3 \%$ and $4 \%$ of moisture content at $20{ }^{\circ} \mathrm{C}$ and $50{ }^{\circ} \mathrm{C}$. In general $\varepsilon$ ' of ester-pressboard has higher values than oilpressboard at frequencies above $1 \mathrm{~Hz}$. It is because dielectric permittivity of synthetic ester MIDEL is about 3.0 vs. 2.2 for mineral oil.

In some frequency ranges dielectric loss $\varepsilon$ " for esterpressboard and oil-pressboard is similar. In other frequencies there is a big difference, which depends on temperature and moisture content.
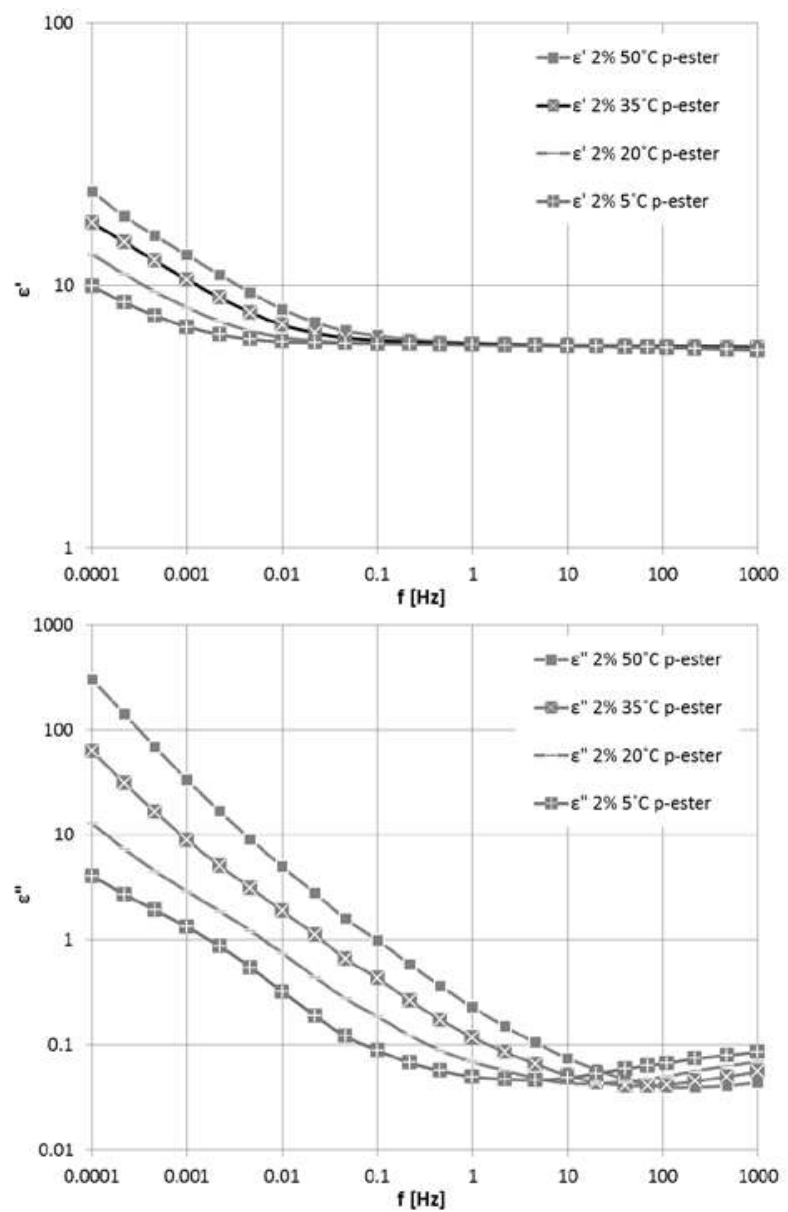

Fig. 4 - Dielectric response of synthetic ester impregnated pressboard with $2 \%$ moisture content at various temperature values: $5,20,35$ and $50{ }^{\circ} \mathrm{C}$

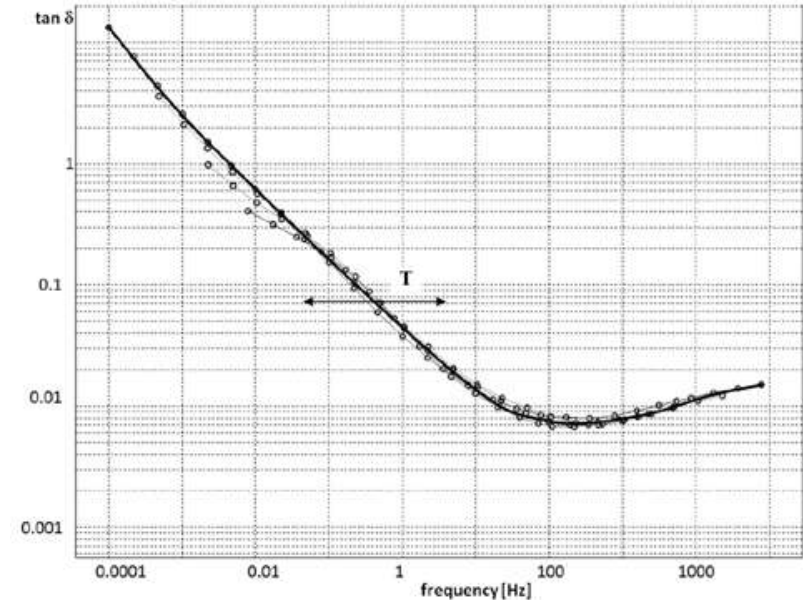

Fig. 5 - Dielectric response (as $\tan \delta$ ) of $2 \%$ moisture content samples measured at different temperatures and shifted with activation energy $0.8 \mathrm{eV}$ to $50{ }^{\circ} \mathrm{C}$ and derived master curve (solid line)
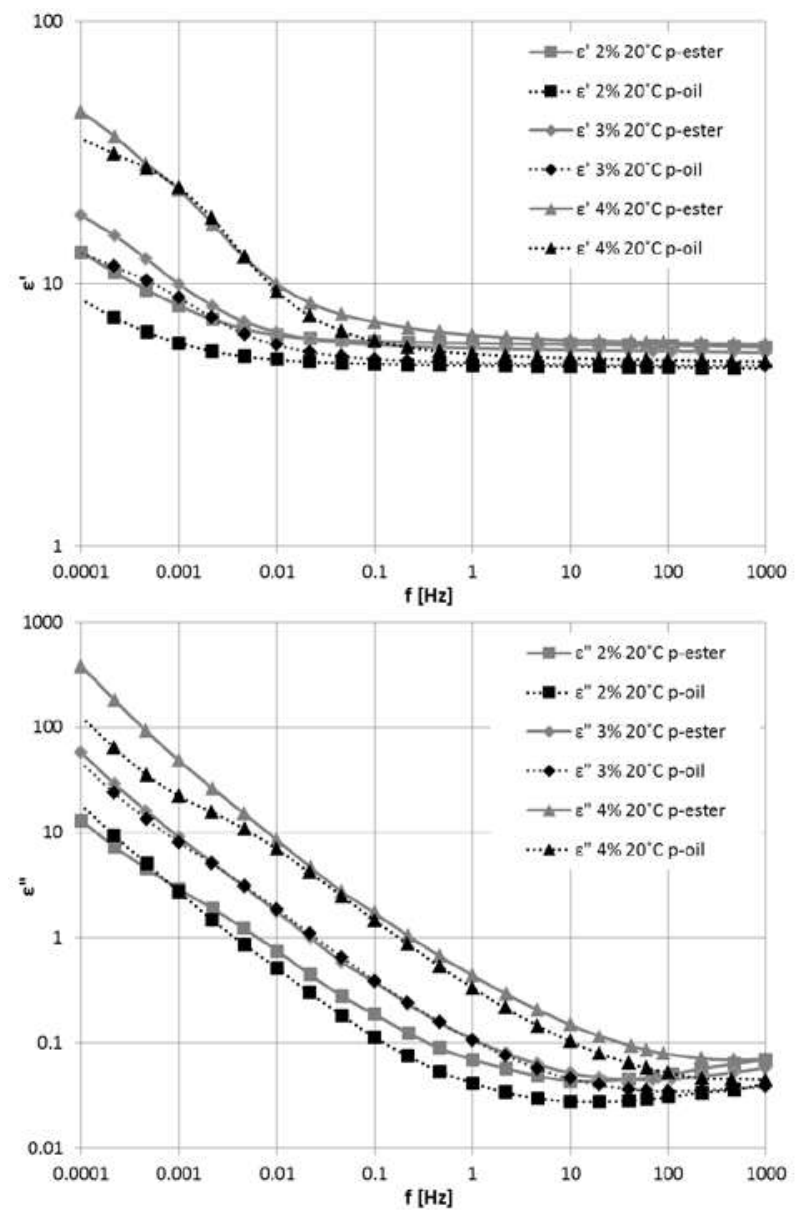

Fig. 6 - Comparison of dielectric response for synthetic ester impregnated pressboard and mineral oil impregnated pressboard with various moisture content: $2,3,4 \%$ at $20{ }^{\circ} \mathrm{C}$ 

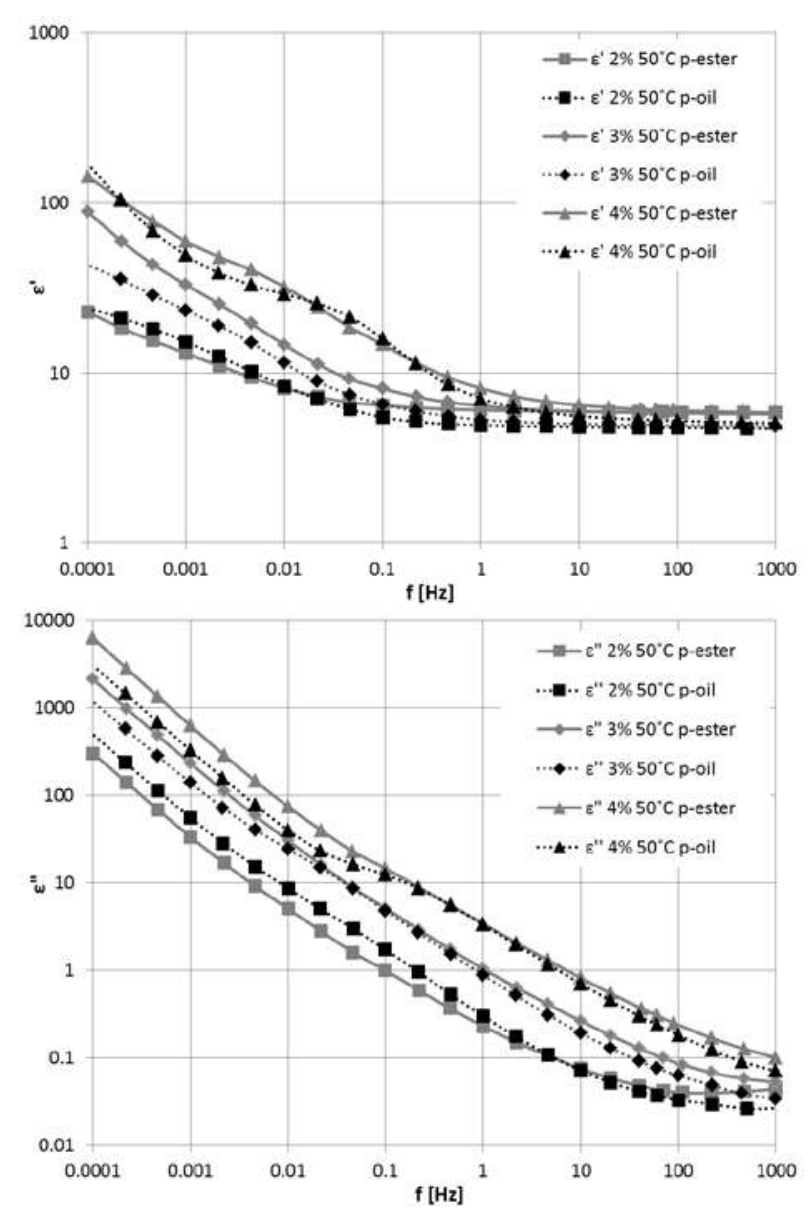

Fig. 7 - Comparison of dielectric response for synthetic ester impregnated pressboard and mineral oil impregnated pressboard with various moisture content: $2,3,4 \%$ at $50{ }^{\circ} \mathrm{C}$

\section{Conclusion}

The moisture and temperature have great influence on dielectric response of natural ester impregnated pressboard.

Influence of temperature can be modeled by master curve technique.

Dielectric response has features of low frequency dispersion (LFD) [7]. For decreasing frequency (in log$\log$ plot) there is almost linear increase of $\varepsilon$ ". There is also an increase of $\varepsilon$ ', which is related to charge storage in a system. Linear increase of $\varepsilon$ " with slope -1 reflects conduction but the increase of $\varepsilon$ ' does not appear in case of pure conduction.

Variation of dielectric response for mineral oilpressboard in comparison to synthetic ester-pressboard is similar but not identical. For particular combinations of temperature and moisture content the difference is significant in some frequency range.

Accurate moisture evaluation of pressboard impregnated with ester using FDS technique needs a new pattern database different from that for oil-pressboard.
[1] R. Martin, H. Athanassatou, J. C. Duart, C. Perrier, I. Sitar, J. Walker, C., "Experiences in service with new insulating liquids", Working Group A235, CIGRE, Oct. 2010

[2] Hopkinson, P.; Dix, L.; McShane, C.P.; Moore, H.R.; Moore, S.; Murphy, J.; Prevost, T.; Beaster, B., "Progress report on natural esters for distribution and power transformers," Power \& Energy Society General Meeting, 2009. PES '09. IEEE, vol., no., pp.1,3, 26-30 July 2009

[3] Graczkowski A.; Gielniak J., "Influence of impregnating liquids on dielectric response of impregnated cellulose insulation," Solid Dielectrics (ICSD), 2010 10th IEEE International Conference on , vol., no., pp.1,4, 4-9 July 2010

[4] J. Hao, Z. Ma, R. Liao, G. Chen, and L. Yang, "A comparative study of moisture and temperature effect on the frequency dielectric response behaviour of pressboard immersed in natural ester and mineral oil", XVII International Symposium on High Voltage Engineering, Hannover, Germany, August 22-26, 2011

[5] Ekanayake, C.; Gubanski, S.M.; Graczkowski, A.; Walczak, K., "Frequency response of oil impregnated pressboard and paper samples for estimating moisture in transformer insulation," Power Delivery, IEEE Transactions on , vol.21, no.3, pp.1309,1317, July 2006

[6] Werelius, P.; Jialu Cheng; Ohlen, M.; Robalino, D.M., "Dielectric frequency response measurements and dissipation factor temperature dependence," Electrical Insulation (ISEI), Conference Record of the 2012 IEEE International Symposium on, vol., no., pp.296,300, 10-13 June 2012

[7] Jonscher, A.K., "The universal dielectric response and its physical significance," Electrical Insulation, IEEE Transactions on, vol.27, no.3, pp.407,423, Jun 1992

Research was done within the framework of research project financed by The National Centre for Research and Development NCBiR, no. NR01-0004-10/2010

\section{References}

